\title{
O MUNDO FLUTUANTE DE LEONARDO FRÓES
}

THE FLOATING WORLD OF LEONARDO FROÉS

FRÓES, LEONARDO. TRILHA (POEMAS 1968-2015). RIO DE

JANEIRO: AZOUGUE EDITORIAL, 2015.

Victor da Rosa*

Não poderia haver título mais feliz para esta nova antologia de Leonardo Fróes, Trilha, que reúne alguns de seus poemas desde 1968, quando publicou seu primeiro livro, Lingua franca, até três inéditos recentes.

Primeiro porque a palavra do título nos coloca diante da relação intensa e pessoal do poeta com a natureza - em 1970 Fróes resolve se isolar em um sítio de um distrito no Rio de Janeiro, onde vive até hoje. Tal relação, embora bastante evidente em seus poemas, principalmente no que diz respeito ao tema, ainda não parece ter sido analisada com o alcance que merece, mesmo porque, desta vez, o reaparecimento da obra de Fróes acontece em um momento bastante particular do país, em que o tema ambiental é ainda mais urgente - fazendo parte, como nunca, de nossa pauta política. ${ }^{1}$
* victordarosa@gmail.com

Doutor em literatura pela Universidade Federal de Santa Catarina.

A ideia de trilha, além de sugerir a relação entre a poesia de Fróes e o ambiente onde o poeta vive, estabelece também um modo específico de como essa relação acontece. Por um lado, não se trata de um gesto contemplativo e tampouco idílico; por outro, a natureza nos poemas de Fróes não é propriamente ameaçadora, pelo menos no sentido mais corrente. Nesse caso, a ideia de trilha parece nos indicar uma constante experiência entre os caminhos da mata, ou seja, trata-se de uma relação notadamente experimental - de panes, recomeços, pesquisa, sustos, suspensões, erotismo, prazer, certa sabedoria e muitas descobertas. A rigor, a ida de Fróes para a mata, além de uma escolha pessoal, é também uma opção poética.

No poema em prosa "Sim", temos a indicação de que “A experiência entra pelos poros"; ${ }^{2}$ já em "Quebra-corpo", 
3. FRÓES. Trilha, p. 34.

4. FRÓES. Trilha, p. 30.

5. FRÓES. Trilha, p. 30. temos outra solução para a mesma ideia, quando o poema diz sobre "essa lenta/ experimentação de um corpo que se articula com a tarde/ essa tarde-corpo"; ${ }^{3}$ e finalmente em "Dia de dilúvio", ao se deparar com a água da chuva invadindo sua casa, o poeta sente uma "desproteção total violenta" que acaba lhe dissolvendo também. ${ }^{4}$ Nota-se que o poema em questão, formalmente, feito com uma frase apenas, em um fluxo, se comporta como a própria chuva:

Quando chove assim tão seguidamente na serra e começa a pingar água na casa e a goteira cresce e a pia entope e alaga o chão,

quando não cessa esse barulho insistente de água penetrando em tudo e rolando, sinto uma desproteção total violenta

e eu mesmo sendo dissolvido também nessa casa alagada, não me acho enquanto solidez: vou flutuando como onda inconstante na correnteza. ${ }^{5}$

Talvez seja este o centro da poesia de Fróes: a busca, em meio à natureza, por uma despersonalização. Dificilmente será possível fazer uma leitura "ambiental" de sua poesia contornando tal problema, que também pode nos levar a uma discussão sobre a poesia zen. Muitos poemas, e provavelmente os melhores de toda a trajetória do autor, dão testemunhos belíssimos dessa espécie de suspensão à qual o sujeito é levado ou submetido em contato com a natureza. Dizendo melhor, o sujeito passa a ser ele próprio natureza também. Por exemplo, em "O observador observado", ao olhar um animal atentamente, fazendo dele um verdadeiro objeto de estudo, o poeta necessariamente acaba "largando de lado, no processo, / todo e qualquer vestígio de quem sou”. ${ }^{6}$ Dessa forma, confunde a sua própria consciência com a do bicho. ${ }^{7}$

E o leitor também, seguindo a sugestão do poema que abre o volume, não deve sair ileso da experiência de leitura - o que, aliás, talvez demonstre certo aspecto participante da poesia de Fróes, quem sabe a sua principal ligação com os movimentos de arte da década de 1970, que é de onde afinal o poeta surgiu. ${ }^{8}$ Intitulado "Leitora", o poema descreve uma mulher lendo, sentada embaixo de uma árvore, mas que aos poucos vai sendo percorrida por uma "chuva ou saraivada de insetos", ficando em aberto se os insetos são ou não uma consequência imaginária do ato de leitura. Após pousarem em seu corpo, "nos seus ombros nus, nos braços/ e no cabelo sedoso", os insetos terminam não por oferecer incômodo, mas servindo de adorno: "como joias raras,/ como broches vivos".

Um segundo aspecto da ideia de trilha, na medida em que faz referência à prática das caminhadas, diz respeito a outro sentido possível que podemos depreender do título: agora é o leitor quem caminha por meio da obra do poeta,
6. FRÓES. Trilha, p. 20.

7. A este respeito, lembrar do célebre ensaio de Jacques Derrida em que, ao olhar para o animal, o filosofo passa a suspender o limite entre quem animal que logo sou).

8. Ver, por exemplo, a tese de Flávia Cera a respeito de Hélio Oiticica, Arte-vida-corpo-mundo cujo pressuposto consiste em interrogar as consequências do pensamento de Oiticica sobre a arte em relação ao conceito de espectador. Para a autora, ao abandonar uma concepção do objeto de arte autônomo, o artista inverte as noções de espectador e participador, iniciando assim uma política de alteridade (CERA. Arte-vida-corpo-mundo).

9. FRÓES. Trilha, p. 13.

$\begin{array}{lllllll}\text { EM TESE } & \text { BELO HORIZONTE } & \text { v. } 23 & \text { N. } 1 & \text { JAN-AB8. } 2017 & \text { ROSA. } 0 \text { mundo flutuante de Leonardo Fróes } & \text { P. } 308-311\end{array}$


10. FRÓES. Trilha, p. 44. percorrendo e assim descobrindo a sua própria trilha. Ler, nesse caso, é exatamente como caminhar, com suas "dificuldades" e "comodidades resolvidas", seguindo o poema "Caminhadas". ${ }^{10}$ No caso de "Introdução à arte das montanhas", um dos mais marcantes da obra de Fróes, nos deparamos com este relato sobre um animal - é o leitor o animal? Ou o próprio poeta? - que passeia nas montanhas:

Um animal passeia nas montanhas.

Arranha a cara nos espinhos do mato, perde o fôlego mas não desiste de chegar ao ponto mais alto

De tanto andar fazendo esforço se torna

um organismo em movimento reagindo a passadas, e só. Não sente fome nem saudade nem sede, confia apenas nos instintos que o destino conduz.

Puxado sempre para cima o animal é um ímã, numa escala de formiga, que as montanhas atraem.

Conhece alguma liberdade, quando chega ao cume. Sente-se disperso entre as nuvens,

acha que reconheceu seus limites. Mas não sabe, ainda, que agora tem de aprender a descer. ${ }^{1}$

Algo interessante a respeito dessa caminhada é que os poemas de Fróes, nesse Trilha, não estão organizados de maneira linear, e sim embaralhados, confundindo suas mais diferentes poéticas ao longo de quase cinquenta anos - $\mathrm{e}$ são muitas as poéticas pelas quais Fróes transitou, como o poema em prosa, a poesia oriental, assim como experiências místicas e certas práticas metalinguísticas, chegando às vezes ao poema-piada, mas quase sempre permeadas por soluções líricas e despojadas, além de uma naturalidade muito sua.

Por fim, e de modo menos evidente, a noção de trilha remete também a uma espécie de música - ou justamente a uma trilha sonora, já que a música em seus poemas parece tão distante, como se tocasse ao fundo, feita pelo próprio ambiente ou incorporada a ele, marcando também o desejo de silêncio da poesia do autor. Uma característica dessa música é sua lentidão, mas não a monotonia, que se associa ao tema da paciência: "Nem saudade nem pressa: paciência./ Aprender essa arte,/ conjugá-la com a sorte”. ${ }^{12}$ Depois, por meio de um fraseado às vezes muito próximo à prosa, com poemas que também se parecem com pequenos contos ou mesmo fábulas, os poemas de Fróes mimetizam o ritmo da mata - algo do barulho do vento ou da fluidez da água - captando assim um mundo flutuante.

Talvez seja esta a aposta da poesia de Leonardo Fróes: ao buscar uma vida e um espaço poético além do limite (urbano, poético, geracional), o poeta se orienta, e nos alerta, a "ouvir a canção além dos passos/ e além de sua própria pessoa", ${ }^{13}$ ou seja, trata-se de uma "poética do sensível" - de acordo com a sugestão do editor Sergio Cohn na apresentação do volume,
12. FRÓES. Trilha, p. 126.

13. FRÓES. Trilha, p. 32

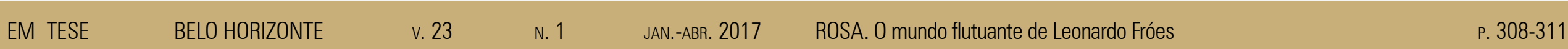


14. COCCIA. A vida sensível.

ao associá-la ao pensamento de Emanuele Coccia ${ }^{14}$ - já que "não possui nada de especificamente humano". É uma aposta positiva, mas muito crítica, e também por isso desafiadora.

Que o lançamento deste livro possa fazer a experiência, a poesia e o pensamento-rio deste poeta desaguar em outros rios, no próprio mar. Quanto a nós, leitores, seguimos na trilha de Fróes.

\section{REFERÊNCIAS}

CERA, Flávia. Arte-vida-corpo-mundo segundo Hélio Oiticica.

Tese (Doutorado). Universidade Federal de Santa Catarina,

Programa de Pós-Graduação em Literatura, 2012.

COCCIA, Emanuele. A vida sensível. Trad. Diego Cervelin. Desterro: Cultura e Barbárie, 2010.

DANOWSKY, Déborah; VIVEIROS DE CASTRO, Eduardo. Há

mundo por vir? Florianópolis: Cultura e Barbárie, 2014.

DERRIDA, Jacques. $\mathbf{O}$ animal que logo sou. Trad. Fábio Landa. São Paulo: Editora UNESP, 2002.

FRÓES, Leonardo. Trilha (poemas 1968-2015). Rio de Janeiro: Azougue Editorial, 2015. 